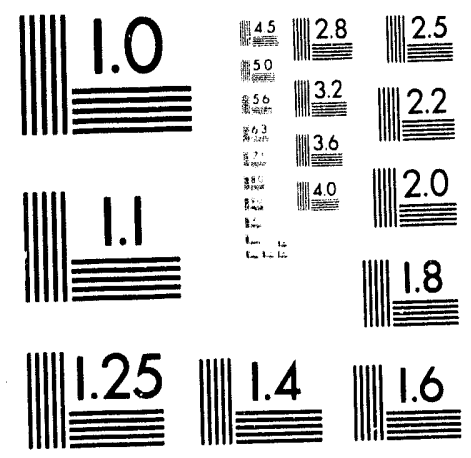

1.4 

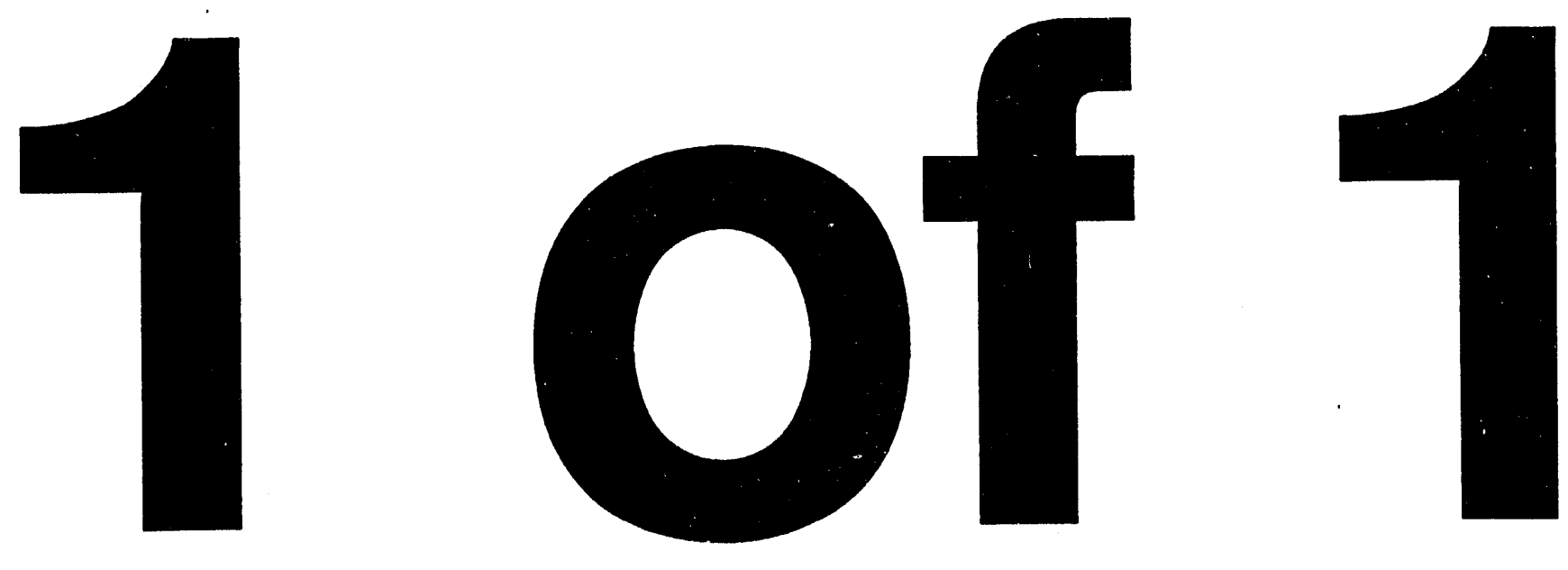


\section{TRANSMISSION ELECTRON MICROSCOPY STUDY OF THICK COPPER-304 STAINLESS STEEL MULTILAYERS}

M.A. Wall

T.W. Barbee, Jr.

T. Weihs

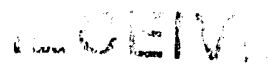

ост 141993

OSTI

This paper was prepared for submittal to the

Materials Research Society Spring Meeting

San Francisco, CA

April 12-16, 1993

June 8, 1993

This is a preprint of a paper intended for publication in a joumal or proceedinga. Since changes may be made before publication, this preprint is made available with the understanding that it will not be cited or reproduced without the permission of the author. 
DISCLAIMER

This docwment was prepared as an accouat of work apoweoned by an agency of the United States Government. Neither tbe United States Government nor the University of California nor any of their employees, makes any warranty, express er inplied, or assumes any legal liability or responsibility for the acceracy completencesen, or usefulwess of any information, apparates, product, er process disclosed, or represents that its use would not infringe privately owned rights. Refereace herein to any spectic commercial products, process, or service by trade mane, trademasks manufacturer, or otherwise, does not wecessarily constitute or imply its endorsement, recommendation. or favoring by the United States Goverament $o r$ the University of Callifornia. The views and opinions of authors expressed berela do wor mecessarilly wate or reflect those of the United States Government or the University of Californian and shall not be used for advertising or product endorsemeat parposes. 
TRANSMISSION ELECTRON MICROSCOPY STUDY OF THICK COPPER-304 STAINLESS STEEL MULTILAYERS

M. A. WALL, T. W. BARBEE, Jr. AND T. WEIHS

Lawrence Livermore National Laboratory

Chemistry and Materials Science Department

Livermore, CA U.S.A. 94550.

\section{ABSTRACT}

Thick (10 to $25 \mu \mathrm{m}$ ), free-standing, equal layer thickness, Copper $(\mathrm{Cu})-304$ Stainless Steel(SS) multilayer foils, having periods of $1 \mathrm{~nm}$ to $100 \mathrm{~nm}$, synthesized by magnetron sputter deposition, have been examined by plan view and cross-sectional transmission electron microscopy. Multilayer growth morphology, individual layer structure and crystallographic phase orientation relationships were characterized in this study. Electron Energy Loss filtered imaging of a $20 \mathrm{~nm}$ period multilayer cross-section was also performed and showed that nickel had diffused into the $\mathrm{Cu}$ layers from the SS during synthesis. $X$-ray powder diffraction scans were performed and analyzed. A pure deposit of 304SS was synthesized and had a metastable BCC structure. Multilayer samples having periods of $20 \mathrm{~nm}$ were found to have a coherent layered $\mathrm{Cu}(\mathrm{FCC})$ SS(FCC) structure. At larger periods $(50 \& 100 \mathrm{~nm})$ a bimodal Cu(FCC)-SS(FCC \& BCC) structure was formed. These observations show that the 304SS will grow with a metastable BCC structure when sputter deposited. When layered with $\mathrm{Cu}(\mathrm{FCC})$ the $304 \mathrm{SS}$ has its equilibrium FCC structure at layer thicknesses up to $10 \mathrm{~nm}$ as a result of epitaxy with the copper. At larger SS layer thicknesses the SS appears to locally transform to the metastable BCC structure during synthesis, refining the grain structure of the depositing SS layer and the subsequent $\mathrm{Cu}$ layer. This transformation significantly increases the strength of the larger period multilayer.

\section{INTRODUCTION}

Multilayers are dense ultra-fine grained high interface concentration solids. As a result of the atomic level structural and chemical control provided by multilayer synthesis techniques, materials having unique structures and physical properties not accessible by conventional processing may be created. Transmission Electron Microscopy (TEM) characterization provides important information enabling correlation of the atomic level structure and the properties of these nano-structured materials. These correlations are clearly important in the development of new multilayer materials of technological importance. Current multilayer applications include $x$-ray and neutron optics, protective coatings, magnetic thin films, integrated circuit interconnects and potentially, structural components.

Reported TEM characterization of multilayered films has been primarily for samples $\leq 1 \mu \mathrm{m}$ thick $[1,2]$. Recent advances in multilayer synthesis technology have made possible fabrication of substantially thicker multilayer structure foils (>250 $\mu \mathrm{m}$ thick). In the past, multilayer characterization has emphasized interfaces in multilayer materials (i.e. interface morphology, structure, chemical abruptness and stability). The increase in multilayer thickness from film dimensions $(t<1 \mu \mathrm{m})$ to foil thicknesses $(t>10 \mu \mathrm{m})$ results in the need for characterization of multilayer structural morphology over large distances. Preparation of specimens with large viewing areas is increasingly important, particularly in cross-section. Such techniques have been applied in this work, allowing detailed study of the mutilayer as a function of position in the structure at scales varying from atomic to micro-structural. In this paper results of a TEM study of thick $(10$ to $25 \mu \mathrm{m})$ CU-304SS multilayers synthesized by magnetron sputtering are reported. These materials are both face-centered-cubic (FCC) in

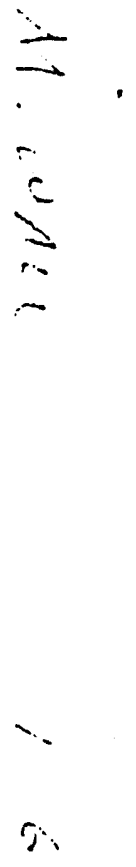


equilibrium and highly ductile. Additionally, the major elemental components in the $304 \mathrm{SS}(\mathrm{Fe}, 72$ at $\%$; $\mathrm{Cr} 18$ at $\%)$ are insoluble in $\mathrm{Cu}$ so that stable chemically abrupt interfaces were expected.

\section{EXPERIMENTAL}

$\mathrm{Cu}-304 \mathrm{SS}$ multilayers were synthesized by multiple source magnetron sputter deposition (MSD) onto device quality three and four inch diameter single crystal silicon $\{(111) \&(100)\}$ wafers mounted on a rotating table [3] with periods ranging from $1-100 \mathrm{~nm}$ and total film thicknesses of $10-25 \mu \mathrm{m}$ (Table 1). The 304SS target composition is 72 at \% Fe, 18 at $\% \mathrm{Cr}, 8$ at $\% \mathrm{Ni}$ (with minor constituents $\mathrm{C}, \mathrm{Si}, \mathrm{Mn}, \mathrm{P}$ and $\mathrm{S}$; total $<3$ at \%). The target power and rotation speed were varied in order to control the multilayer periods. Deposition times ranged from 3 to 6 hrs. The substrates were thermally floating and reached temperatures of 200 to $250 \mathrm{C}$ during the highest power deposition experiments. Both plan view and $x$-sectional specimens [4] were prepared for TEM. Conventional TEM (CTEM) was performed of a JEOL 200CX and high resolution TEM (HREM) was performed of a JEOL $4000 \mathrm{EX}$. Inelastically scattered energy filtered images were acquired on a JEOL $1200 \mathrm{EX}$ fitted with a Gatan Image Filter (GIF) [5]. Standard powder diffraction Bragg-Bretano $x$-ray scans were preformed on a Philips XRG 3100.

Table 1. Copper-304 Stainless Steel multilayered samples.

\section{Layer Thickness}

\begin{tabular}{|c|c|c|c|c|c|}
\hline Sample \# & $\mathrm{Cu} \mathrm{t}(\mathrm{nm})$ & $S S t(n m)$ & Period (nm) & $\mathbf{N}$ & Thickness \\
\hline $\begin{array}{l}289.016 \\
289.011 \\
289.021 \\
289.013 \\
289.008 \\
289.019 \\
289.012 \\
289.014 \\
289.015 \\
289.032\end{array}$ & $\begin{array}{l}.49 \\
.99 \\
1.35 \\
2.47 \\
3.75 \\
4.96 \\
9.90 \\
24.7 \\
49.4 \\
0.0\end{array}$ & $\begin{array}{l}.494 \\
.98 \\
1.34 \\
2.49 \\
3.75 \\
4.96 \\
9.90 \\
24.7 \\
49.8 \\
5000\end{array}$ & $\begin{array}{l}.984 \\
1.97 \\
2.69 \\
4.96 \\
7.5 \\
9.92 \\
19.8 \\
49.8 \\
99.2 \\
5000\end{array}$ & $\begin{array}{l}10162 \\
9653 \\
6499 \\
5000 \\
3333 \\
2170 \\
1002 \\
400 \\
200 \\
1\end{array}$ & $\begin{array}{l}9.99 \\
1.90 \\
17.48 \\
19.83 \\
25.0 \\
21.52 \\
19.83 \\
19.8 \\
19.8 \\
5.0\end{array}$ \\
\hline
\end{tabular}

\section{OBSERVATIONS}

X-ray diffraction (XRD) scan results (Fig. 1) on samples having periods of $2,7.5,50$ and $100 \mathrm{~nm}$ show the samples to be highly textured with the (111) planes of the FCC-Cu and 304SS layers to lie in the plane of the foil. Side bands resulting from the layering are seen in the scans of the 2 and $7.5 \mathrm{~nm}$ period samples. The 50 and $100 \mathrm{~nm}$ period samples contain a mixed FCC-BCC diffraction structure indicating that the samples contain substantial metastable BCC 304SS. Continuously deposited and layered $(3 \mathrm{~nm}) 304 \mathrm{SS}$ samples were found to be fully metastable BCC.

Cross-sectional TEM revealed columnar growth structure and well defined layering for all periods. The maximum columnar widths ranged from $.08 \mu \mathrm{m}$ to $0.3 \mu \mathrm{m}$. The smaller period $(\leq 20 \mathrm{~nm})$ films have the wider continous columns as seen in Figure 2 a. The $100 \mathrm{~nm}$ period samplos have discontinuous columnar grains (Figure 3), and the $50 \mathrm{~nm}$ sample was mixed continuous/discontinuous. The continuous columnar growth structures varied systematically as a function of position relative to the substrate. Layers near the substrate were flat consisting of $.01 \mu-.04 \mu \mathrm{m}$ wide columnar grains (Figure 2b). Contined columnar growth resulted in the development of a convex growth surface marked by the chemical layering as the columnar widths increased to a steady-state size (Figure 2b). Plan 


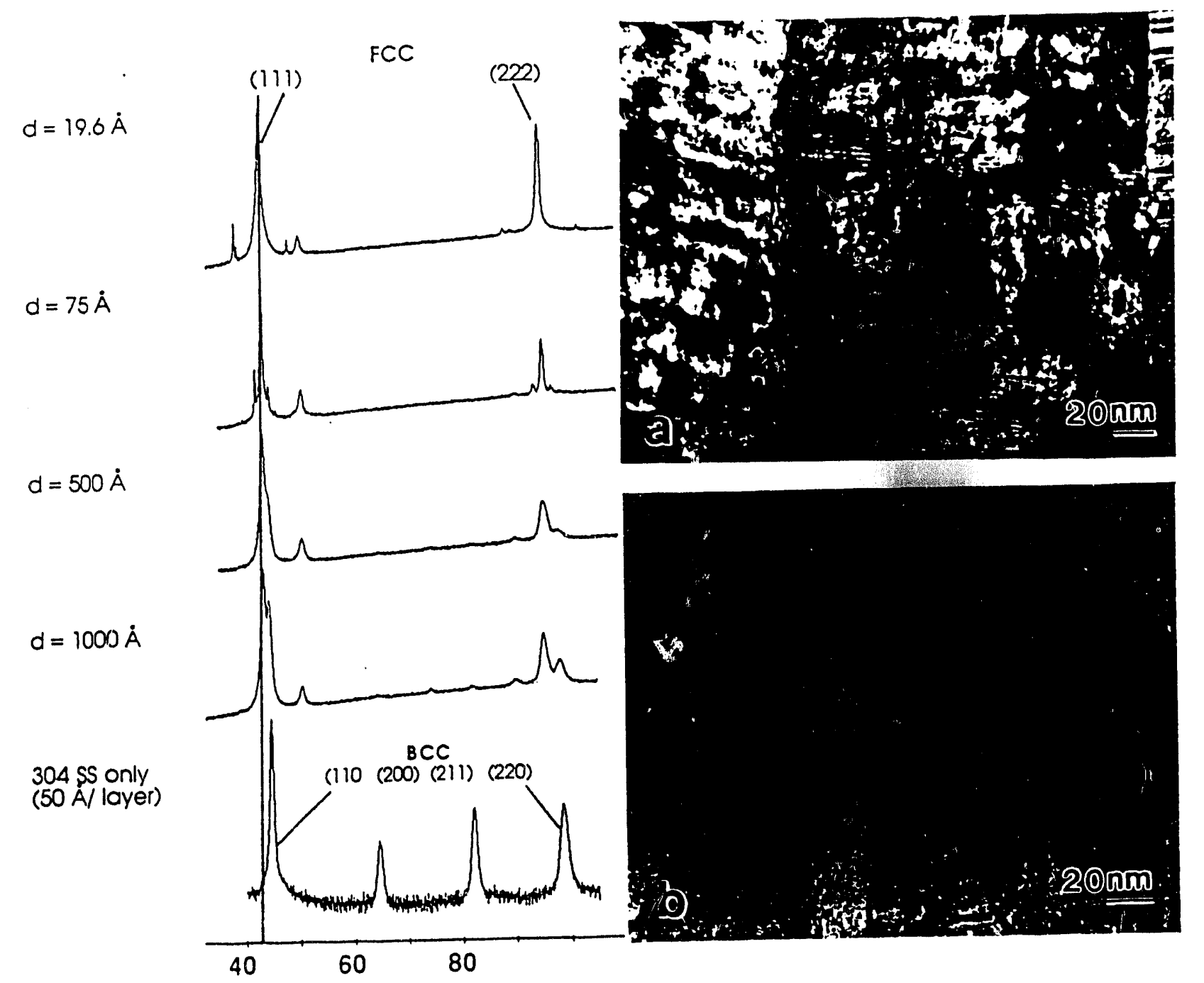

Figure 1. X-ray diffraction scans results of samples having repeat periods of $2,7.5,50,100 \mathrm{~nm}$ and a pure $304 \mathrm{SS}$ deposit. Wavelength= $\mathrm{Cu}$-Kalpha

view observations showed equiaxed columnar grain cross-sections and selected area diffraction (SAD) indicated that the columns are randomly oriented in plane.

Samples with periods $\leq 20 \mathrm{~nm}$ were wholly FCC with (111) planes lying normal to the growth direction. The only other structural feature common for all the different thickness foils, other than columnar boundaries, were (111) growth plane twining which is continous across the width of the columnar structure (Figure 4). The twin boundaries crystallographically define the position of the (11i) planes in the FCC $\mathrm{Cu}$ and 304SS. Even for considerable convex curvature in the columnar growth surfaces and hence, the layer morphology, the twins show that the (111) planes are continuously traversing the oblique interfaces between the $\mathrm{Cu}$ and 304SS layers.

Samples with periods $\geq 50 \mathrm{~nm}$ have a bimodal $\mathrm{Cu}$ (FCC)/304SS (FCC,BCC) structure. A large volume fraction (which increases with the multilayer period) of the 304SS layers have the BCC structure, in agreement with the XRD results. TEM and HREM demonstrate the existence of a number of 304SS BCC morphologies. Figure 5 shows a large single 304SS BCC grain encompassing nearly one half the columnar width. A second observed morphology consists of smaller polycrystals of BCC 304SS within a columnar structure. These two observations are typical examples of continous columnar growth with partial transformation of the FCC 304SS layers to a BCC structure. In the largest period sample $(100 \mathrm{~nm})$, the majority of the columnar growth is discontinuous with larger polvcrustalline $\mathrm{BCC}$ grains in the $304 \mathrm{SS}$ lavers (Figure 6). 
Electron diffraction (Figure 7) was used to identifiy two preferred orientation relationships between the FCC and BCC 304SS phases: KurdjumovSachs (110)BCC // (111)FCC with [111]BCC // [011]FCC and NishiyamaWasserman (110)BCC // (111)FCC with [011]BCC // [101]FCC. Figure 8 shows HREM images of these two orientation relationships in the $100 \mathrm{~nm}$ period sample. Electron diffraction of the pure $304 \mathrm{SS}$ film revealed a wholly BCC structure. Plan view observations of the pure 304 SS film showed a equiaxed grain structure.

Energy filtered imaging [5] was performed on the $20 \mathrm{~nm}$ period crosssection pecimen. This technique produces a two dimensional image map of the chemistry in which the local intensity is near linearly proportional to the concentration. Chemically discrete layering is observed when $\mathrm{Fe} / \mathrm{Cr}$ and $\mathrm{Cu}$ are imaged and is shown in Figure $9 \mathrm{a}$ and $9 \mathrm{~b}$ respectively. Imaging of $\mathrm{Ni}$, as also seen in Figure 9b, shows a substantial depletion of the $\mathrm{Ni}$ at the 304SS.Cu interfaces. A relative measure of this depletion is plotted in Figure 9c.
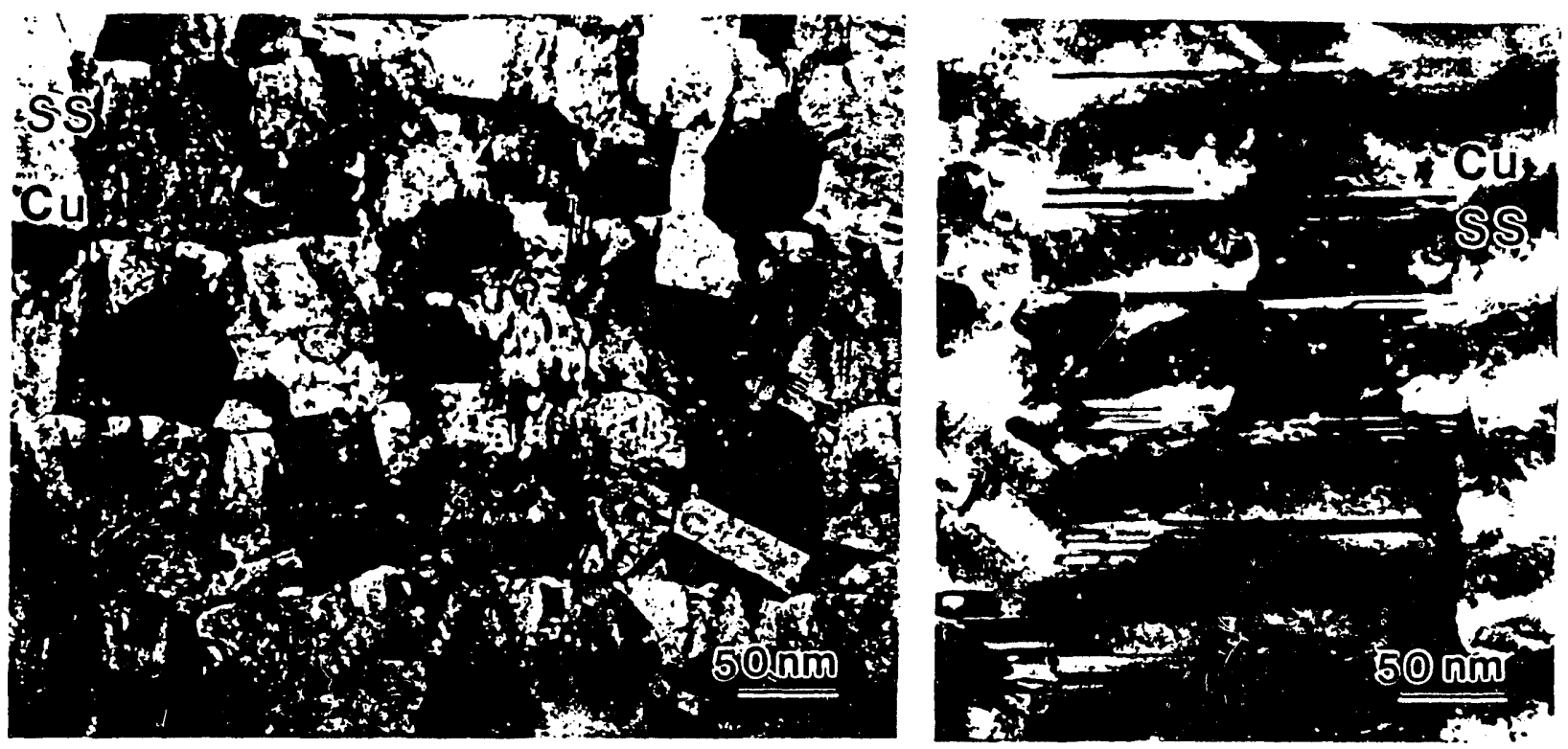

Figure 3. Discontinuous columnar growth and layering, $100 \mathrm{~nm}$ repeat sample.

Figure 4. (111) FCC growth plane twinning, $50 \mathrm{~nm}$ repeat sample.

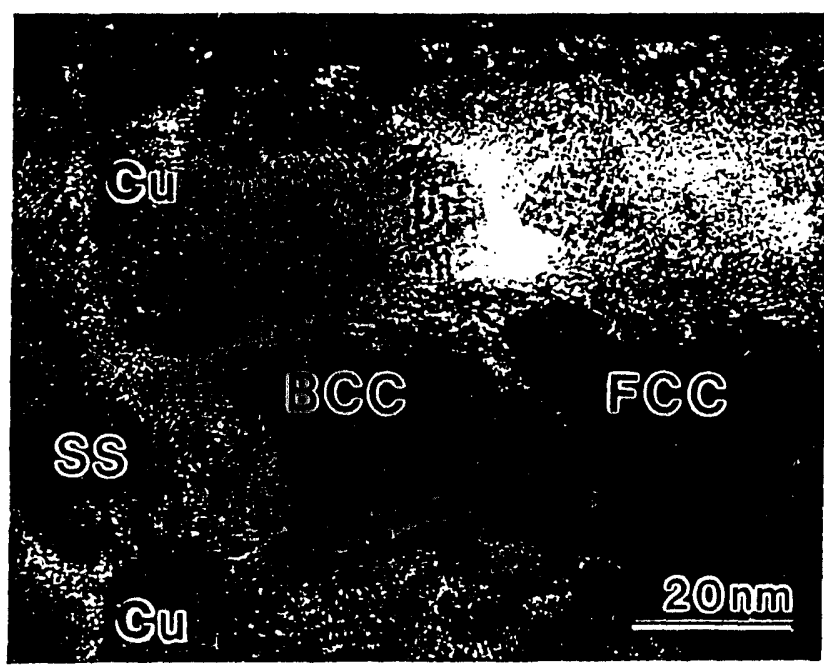

Figure 5. Partial transformation of a single 304SS layer to BCC with in continuous columnar growth structure, $50 \mathrm{~nm}$ repeat sample.

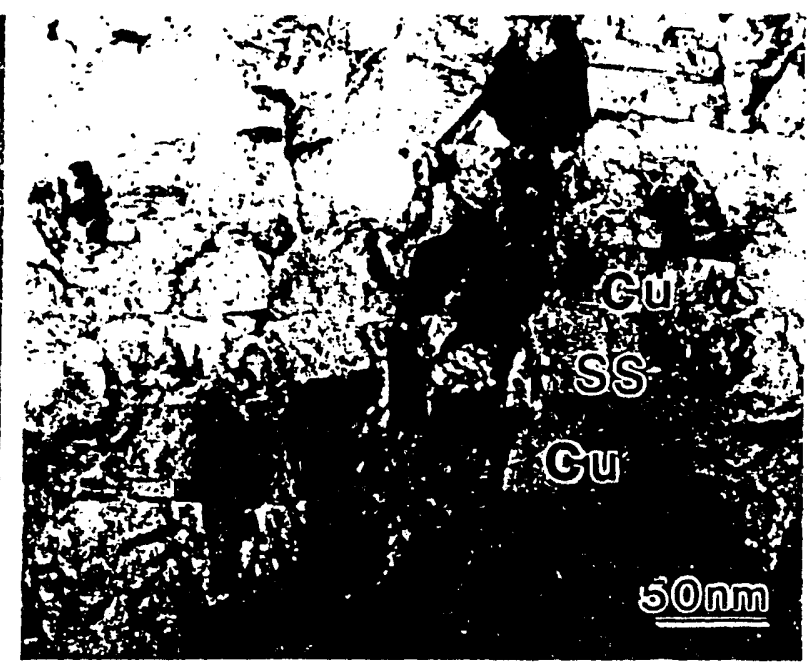

Figure 6. Break up of columnar growth structure, $100 \mathrm{~nm}$ repeat sample. 

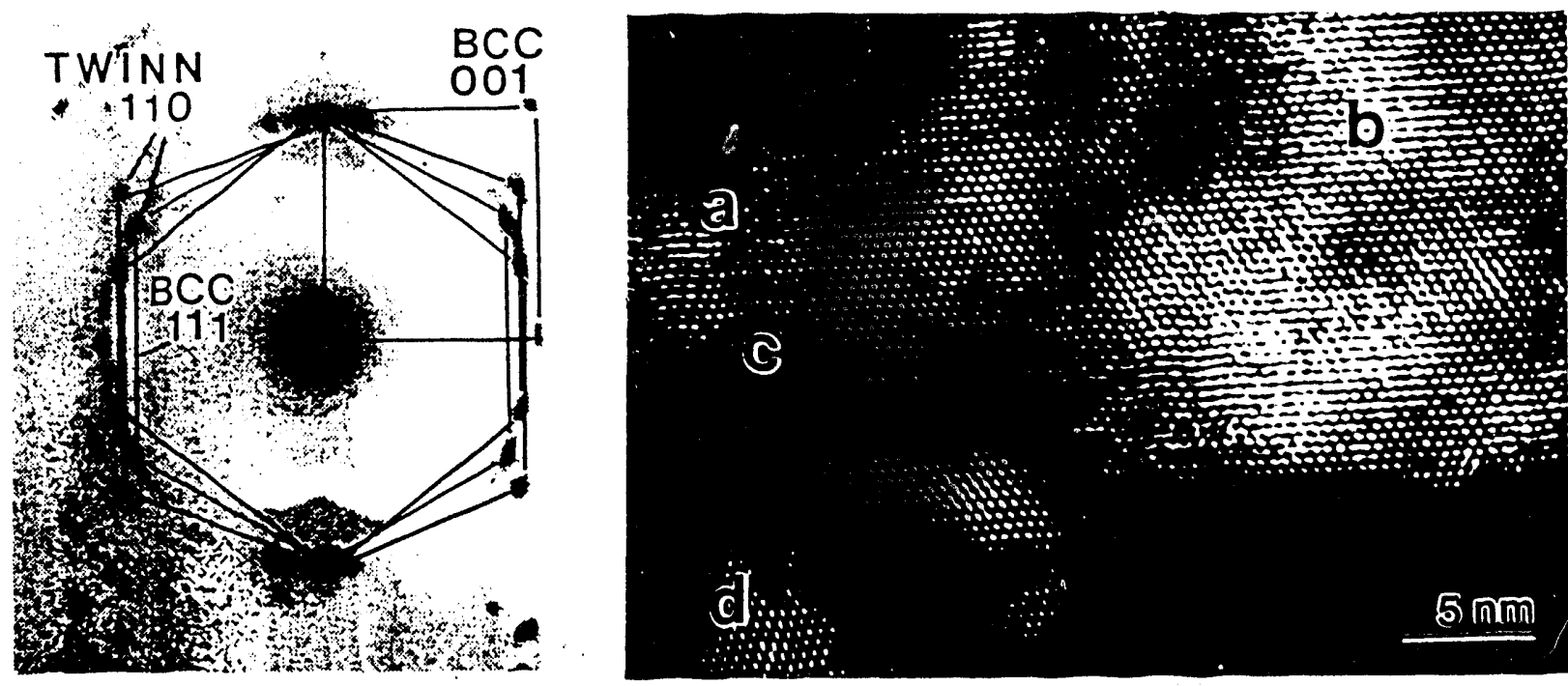

Figure 7. Selected area diffraction Figure 8. HREM of two 304SS orientation pattern showing the two orientation relationships, (a) $[110] \mathrm{BCC}$, (b) [111] $\mathrm{BCC}$, relationships BCC to FCC 304SS. (c) [110] FCC, (d) [110] FCC Cu.
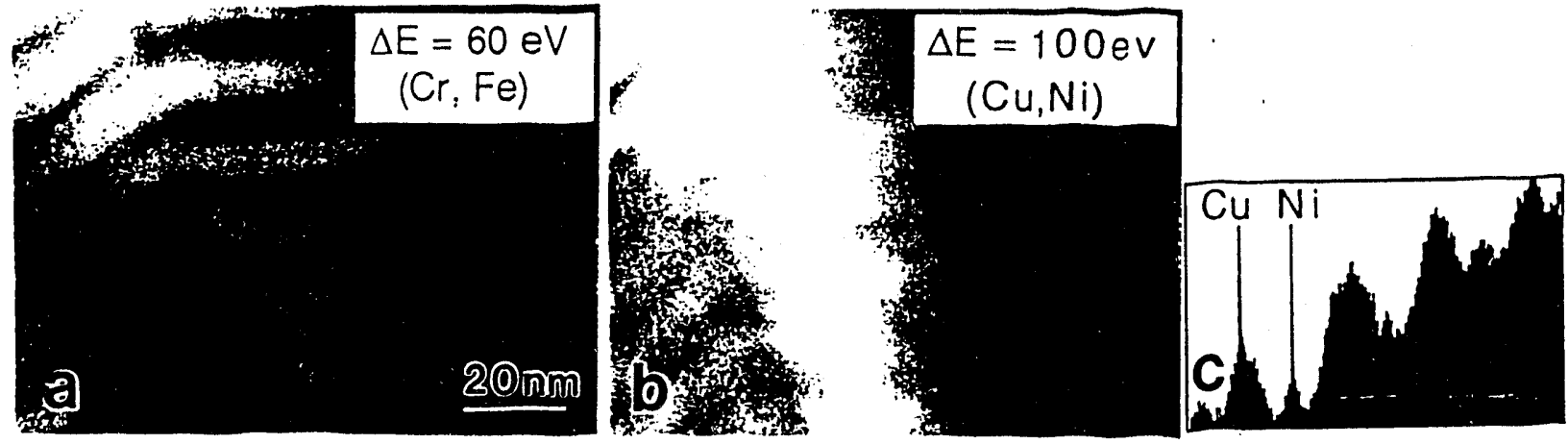

Figure 9. Energy filtered imaging of a $20 \mathrm{~nm}$ repeat sample, (a) Solid solution $\mathrm{Cr}$ and $\mathrm{Fe}$ layering, (b) $\mathrm{Cu}$ and $\mathrm{Ni}$ layering, (c) line profile across 9(b).

\section{DISCUSSION}

The observed metastable BCC structure in the pure $3045 S$ film is believed to be the result of the large $(>1010 \mathrm{~K} / \mathrm{sec})$ surface quench rates available by MSD [6]. As the deposition surface temperature passes through the high temperature $\mathrm{BCC}$ phase field the $\mathrm{BCC}$ structure is quench stabilized [3] by this rapid cooling mechanism. Details of the thermal phase stabilities of $\mathrm{BCC}$ and FCC SS with solidification under non-equilibrium conditions ( i.e. large undercoolings) are reported by [7] and are supportive of this interpertation.

Multilayer samples with periods $\leq 20 \mathrm{~nm}$ were wholly FCC and no interfacial dislocations were observed. Although the deposition of the $3045 S$ resulted in the formation of $\mathrm{BCC} 304 \mathrm{SS}$, when deposited as a multilayer with $\mathrm{Cu}$ only the FCC structure was observed at periods of $20 \mathrm{~nm}$ and less. Therefore, there is a preference for epitaxial growth of FCC 304SS on the similar lattice parameter FCC Cu.

Samples with periods $\geq 50 \mathrm{~nm}$ have a bimodal $\mathrm{Cu}(\mathrm{FCC}) / 304 \mathrm{SS}$ (FCC,BCC) structure. With increasing multilayer repeat period there is an increase in the number of individual SS layers which have undergone a partial transformation from FCC to BCC.This transformation appears to have taken place either in the solid state or during deposition and growth. If the SS layer does not transform to $\mathrm{BCC}$ before the ensuing $\mathrm{Cu}$ layer is deposited then there is continuous columnar growth. If the SS layer transforms from $\mathrm{FCC}$ to a BCC structure during its 
deposition there is not a well defined continuous columnar growth. This formation of BCC 304SS during deposition lead to discontinuous growth and continually refines the columnar size for the larger period multilayer foils (figure 6). This refinement in grain size along with the $\mathrm{FCC} / \mathrm{BCC}$ bimodal structure accounts for the unanticipated increase in the strengths, reported by Barbee [8], for the larger period foils.

Compositional imaging has given us data showing depletion of $\mathrm{Ni}$ from the 304 SS layers at the Cu-304SS interfaces. A steep chemical gradient, very short diffusion path lengths and moderate deposition surface temperatures $\left(\mathrm{T} / \mathrm{T}_{\mathrm{m}} \sim 0.4\right)$ enables diffusion of nickel into the $\mathrm{Cu}$ layer during synthesis. Lower temperature ternary phase diagrams of the $\mathrm{Fe}, \mathrm{Cr}, \mathrm{Ni}$ system calculated by [9] place the nominal $304 S S$ composition near the FCC-FCC+BCC phase boundary. A small Ni composition fluctuations will push the local $304 \mathrm{SS}$ layer composition into the mixed phase $(B C C+F C C)$ region.

The depletion of $\mathrm{Ni}$ in the $304 \mathrm{~S} S$ layers is a driving force for the solid-state transformation of FCC $304 \mathrm{SS}$ to a BCC structure. The $20 \mathrm{~nm}$ repeat sample showed $\mathrm{Ni}$ depletion at the Cu-304SS interfaces but no transformation of FCC $304 \mathrm{SS}$ to $\mathrm{BCC}$. It is possible that coherency strains, along with the fact that the $\mathrm{Ni}$ depleted $304 \mathrm{SS}$ volume is very small, inhibits the FCC to BCC transformation. In the $100 \mathrm{~nm}$ period sample there is transformation of $304 \mathrm{SS}$ layers from FCC to BCC during deposition before the following $\mathrm{Cu}$ layer is deposited. It is likely that either the $\mathrm{Ni}$ depletion is greater with larger 304SS growth layers causing solid-state transformation from FCC to BCC before the ensuing $\mathrm{Cu}$ layer or that the growth of the FCC 304SS layer becomes unstable as it is further isolated from the Cu-SS interface and shifts to a BCC growth structure as in the pure 304SS sample.

\section{CONCLUSION}

TEM observations of Cu-304SS multilayer heterophase growth structures reveals continuous and discontinuous columnar growth with well defined layering throughout the total thickness of the magnetron sputter deposited foils. The transition from continuous to discontinuous columnar growth is a direct result of the deposition parameters; mainly layer pair thickness, and temperature which effects the diffusion of $\mathrm{Ni}$ from the 304SS layers into the $\mathrm{Cu}$ causing a transformation from a FCC $304 S S$ to a BCC structure. These observations by TEM provide a direct link of structure and property and suggest that there are currently no limiting growth defects which will inhibit growing thicker films.

This work was performed under the auspices of the U.S. Department of Energy by Lawerence Livermore National Laboratory under contract No. W-7405-ENG. 48 .

\section{REFERENCES}

[1] C.S. Baxter and W.M. Stobbs, Ultramicroscopy 16, 213-226 (1985).

[2] J.W. Matthews and A.E. Blakeslee, J. Crystal Growth 27, 188-195 (1974).

[3] T.W. Barbee Jr., in Synthetic Modulated structures, (Academic press, 1985), pp.313.

[4] M.A. Wall, in Microbeam Analysis, edited by D.G. Howitt (San Francisco Press Inc., 1991), pp.317.

[5] O.L. Krivanek, A.J. Gubbens, N. Dellby, C.E. Meyer, Microsc. Microanl. Microstrut. 3, 187-199 (1992).

[6] T.W. Barbee, Jr., B.E. Jacobson and D.L. Keith, Thin Solid Films 63, 143. 150 (1979).

[7] T.K. Kelly, M. Cohen, J.B. Vander Sande, Metallurgical Trans. A 15A, 819 (1984).

[8] T.W. Barbee, M.A. Wall, and T. Weihs, MRS Spring Meeting, 1993, Sym $J$ To be published.

[9] V.G. Rivlin and G.V. Raynor, International Metals Rev. 1, 21 (1980). 

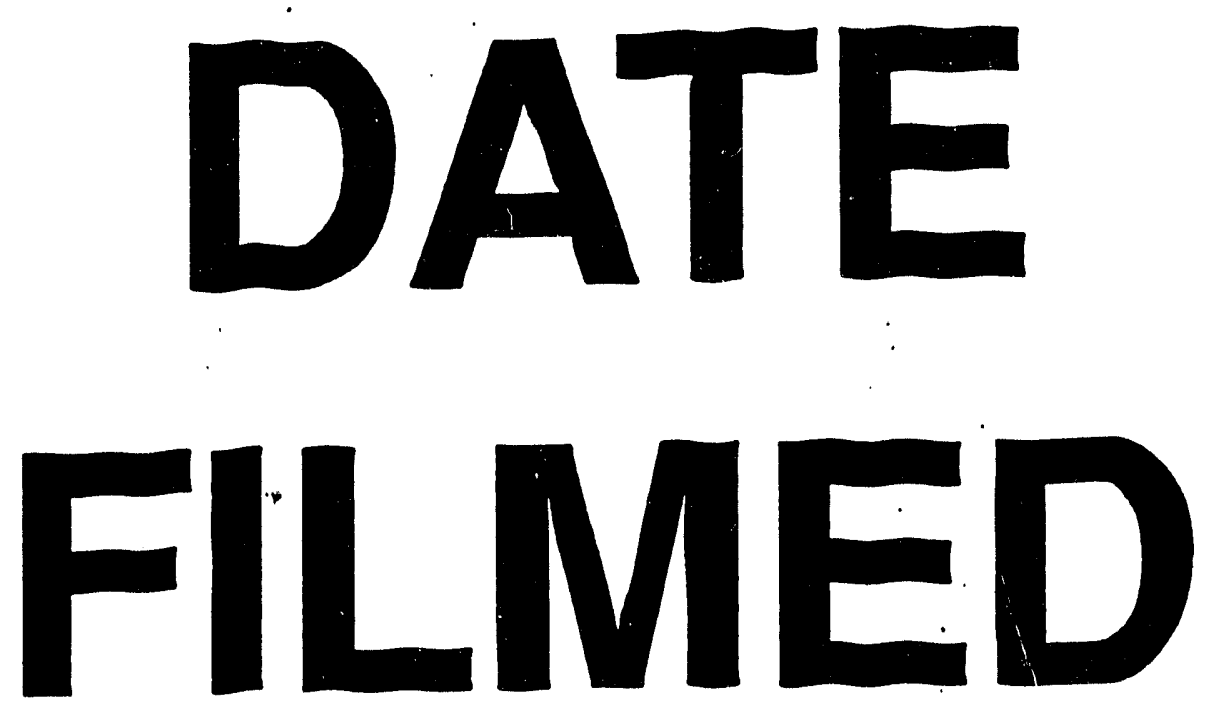

$12 / 10 / 93$
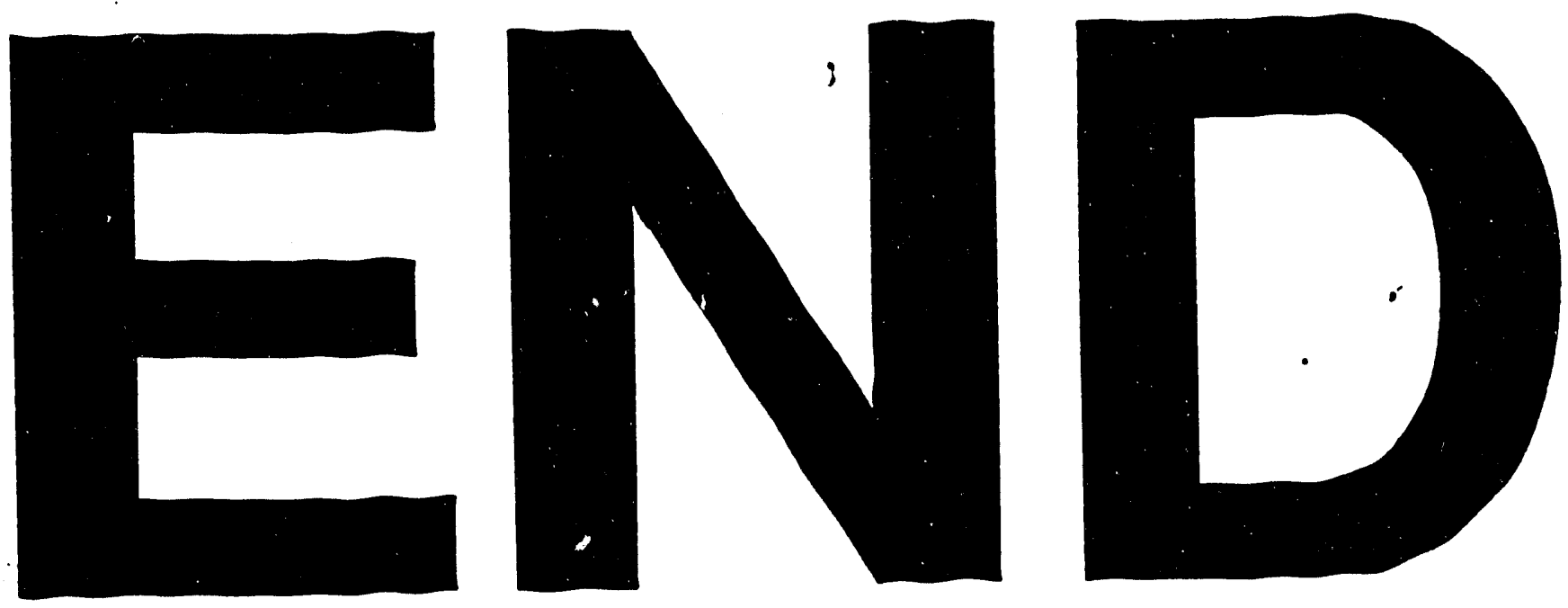
$$
\ldots
$$
$-$ 